\title{
Job dissatisfaction and the older worker: baseline findings from the Health and Employment After Fifty study
}

\author{
Stefania D'Angelo ${ }^{1,2}$ David Coggon, ${ }^{1,2}$ E Clare Harris, ${ }^{1,2}$ Cathy Linaker, ${ }^{1,2}$ \\ Avan Aihie Sayer, ${ }^{3,4,5,1}$ Catharine R Gale, ${ }^{1,6}$ Maria Evandrou, ${ }^{7}$ Tjeerd van Staa, ${ }^{8}$ \\ Cyrus Cooper, ${ }^{1,2}$ Karen Walker-Bone, ${ }^{1,2}$ Keith T Palmer ${ }^{1,2}$
}

\begin{abstract}
- Additional material is published online only. To view please visit the journal online (http://dx.doi.org/10.1136/ oemed-2016-103591).
\end{abstract}

For numbered affiliations see end of article.

\section{Correspondence to Professor Keith Palmer, Medical Research Council Lifecourse Epidemiology Unit, University of Southampton, Southampton General Hospital, Southampton S016 6YD, UK; ktp@mrc.soton.ac.uk \\ Received 22 January 2016 Revised 8 April 2016 Accepted 16 April 2016 Published Online First 5 May 2016}

\section{ABSTRACT}

Objectives Demographic changes are requiring people to work longer. Labour force participation might be promoted by tackling sources of job dissatisfaction. We aimed to describe the epidemiology of job dissatisfaction in older British workers, to explore which perceptions of work contribute most importantly, and to assess possible impacts on health.

Methods Participants aged 50-64 years were recruited from 24 English general practices. At baseline, those currently in work $(\mathrm{N}=5437)$ reported on their demographic and employment circumstances, overall job satisfaction, perceptions of their work that might contribute to dissatisfaction, and their general health, mood and well-being. Associations of job dissatisfaction with risk factors and potential health outcomes were assessed cross-sectionally by logistic regression, and the potential contributions of different negative perceptions to overall dissatisfaction were summarised by population attributable fractions (PAFs).

Results Job dissatisfaction was more common among men, below age 60 years, those living in London and the South East, in the more educated and in those working for larger employers. The main contributors to job dissatisfaction among employees were feeling unappreciated and/or lacking a sense of achievement (PAF 55-56\%), while in the self-employed, job insecurity was the leading contributor (PAF 79\%). Job dissatisfaction was associated with all of the adverse health outcomes examined (ORs of 3-5), as were most of the negative perceptions of work that contributed to overall dissatisfaction.

Conclusions Employment policies aimed at improving job satisfaction in older workers may benefit from focussing particularly on relationships in the workplace, fairness, job security and instilling a sense of achievement.

\section{INTRODUCTION}

The proportion of older people in developed countries is steadily growing, such that by $2060,30 \%$ of the European population will be aged over 65 years. Currently, however, many workers from OECD (Organisation for Economic Co-operation and Development) countries leave the labour market before the normal pension age ${ }^{1}$ and the so-called 'total dependency ratio' (that of those not

\section{What this paper adds}

- Job dissatisfaction can lead to labour turnover and ill health, but little is known at a population level about the negative perceptions of work that contribute most importantly to dissatisfaction, especially in older workers.

- In a large population-based sample of people aged 50-64 years from across England, rates of job dissatisfaction were higher at younger ages, and in men, the better educated, those living alone, workers employed by larger organisations, and those living in London and the South East of England.

- Important potential contributors, as assessed cross-sectionally, included perceptions of job insecurity, feeling unappreciated and unfairly criticised, lacking a sense of achievement at work, and difficult relationships with work colleagues.

- Most of the negative perceptions of work that appeared to contribute to dissatisfaction were associated with worse self-rated health, depression and poor well-being.

- There is a case for employment policies being directed at tackling these potentially avoidable occupational determinants of job dissatisfaction.

working to those in the labour force) is rising. ${ }^{2}$ In response, governments have implemented policies to encourage workers to retire later, including delayed payment of state pensions and reduced pension incentives (to make early retirement less attractive), and legislation against age and disability discrimination (to make employment more flexible and accommodating). ${ }^{3}$

Retention of older workers in the labour market might also be promoted by measures aimed at improving their job satisfaction. Job dissatisfaction has previously been linked with labour turnover, ${ }^{4-6}$ intentions to retire early ${ }^{7-11}$ and sickness absence. ${ }^{12-14}$ However, reports to date have typically focused on selected occupations, ${ }^{15}{ }^{16}$ rather than representative samples of the general population, and there has been little emphasis on the 
older worker. ${ }^{10}{ }^{11}$ As such, the epidemiology of job dissatisfaction in later working life remains ill defined.

A notable area of uncertainty is the relative importance of different negative perceptions of work that might contribute to job dissatisfaction, and whether this varies across subgroups of the population. Job dissatisfaction is a complex phenomenon with many potential determinants, of which some are personal and some relate to the work environment (eg, dissatisfaction with pay or working hours, job insecurity, and problematic relationships with colleagues). However, the most important occupational drivers of dissatisfaction could vary importantly between subgroups defined by age, sex or employment circumstances.

Furthermore, while the link between job dissatisfaction and poorer psychological health is well recognised and much studied,${ }^{17}$ it remains unclear whether some aspects of dissatisfaction are more important than others in influencing workers' health.

This report has three aims relating to these gaps in evidence: (1) to describe the epidemiology of job dissatisfaction in British workers at older ages; (2) to explore the contributions of different negative perceptions of work to overall job dissatisfaction, and whether their relative importance varies across subgroups of the working population; and (3) to determine whether these aspects of dissatisfaction differ in their associations with measures of health.

\section{METHODS}

For our analysis we used baseline data from the Health and Employment After Fifty (HEAF) study, which follows a large population-based cohort of older adults resident in England. The study's design and methods of data collection have been reported in detail elsewhere. ${ }^{18}$ In brief, questionnaires were mailed to 39359 adults born between 1948 and 1962 (target age band at recruitment 50-64 years) from 24 English general practices contributing data to a primary care research database, the Clinical Practice Research Datalink (CPRD). The practices were drawn from every region of England and all deciles of social deprivation, ${ }^{18}$ and all that agreed to support the study became foci of recruitment. Forms were sent to all people in the target age range who were registered with these practices after excluding those with terminal illness or recent bereavement, or who had de-registered between sampling and mailing $(2.5 \%$ of the enumeration list). In all, 8134 participants completed an initial questionnaire during 2013-2014, and are now being followed up annually, initially for a 5 -year period, through further questionnaires and record linkage. Ethical approval was obtained from the National Health Service (NHS) Research Ethics Committee North West-Liverpool East.

Among other things, the baseline questionnaire covered: demographic characteristics; employment status; for those in paid work, its nature and their feelings about working conditions; and self-reported health.

Demographic characteristics relevant to the current analysis were: sex and age; highest educational qualification (school only, vocational training certificate, university or higher professional degree); household composition; and the location of the participant's general practice, which was used to classify them by an area-based measure of deprivation, the English Index of Multiple Deprivation 2010. ${ }^{19}$

Items on the nature of work concerned: the size of an employer's workforce (these were combined with employment status to create a variable with three levels, self-employed, employed and working for a small employer ( $<500$ staff), employed and working for a large employer ( $\geq 500$ staff)); tenure with the same employer ( $<1,1$ to $5,>5$ years); type of contract (permanent vs temporary/renewable) and type of salary (fixed vs paid by output); hours worked per week $(\leq 20,>20$ to $40,>40$ ); shift working (often vs sometimes/rarely/never); entitlement to paid holiday; and whether or not a second paid job was held.

Overall job dissatisfaction was assessed from the question: 'How satisfied have you been with your job as a whole, taking everything into consideration?' Response categories of 'very satisfied' and 'satisfied/fairly satisfied' were combined, as were 'dissatisfied' and 'very dissatisfied', to generate a binary variable 'dissatisfied versus not'.

The questions on feelings about work were designed to ascertain various negative perceptions that might contribute to overall job dissatisfaction: satisfaction with pay and with working hours (scored as for overall dissatisfaction); whether there was choice in the job (often, sometimes, rarely/never) or support from colleagues or managers (often, sometimes, rarely/ never); and whether the respondent felt appreciated at work by others (often, sometimes, rarely/never), had a work colleague who was very difficult to get on with (yes vs no), had been criticised unfairly at work (often, sometimes, rarely/never), or felt insecure in employment, overall and in the event of illness (very secure/secure vs rather insecure/very insecure). Before any associations with other variables were explored, answers to these questions were reclassified to create a set of binary variables.

Finally, three self-reported measures of health were assessed: self-rated health (SRH), determined with a single question ${ }^{20}$ and dichotomised (as fair/poor vs at least good); depressive symptoms, assessed by the Centre for Epidemiologic Studies Depression scale (CES-D) with participants scoring $\geq 16$ considered 'depressed'21; and well-being (measured using the Warwick-Edinburgh Mental Well-being Scale (WEMWBS), with participants in the lowest quintile of scores classified as having 'poor' well-being (score $<32$ ). ${ }^{22}$

Analysis was restricted to respondents in paid work who completed the question on overall job satisfaction. In evaluating the epidemiology of job dissatisfaction at older ages, its associations with demographic factors and employment conditions were estimated using logistic regression, with results expressed as ORs with 95\% CIs. Risk estimates were initially adjusted for age and sex, and then derived from mutually adjusted models.

In exploring negative perceptions of work that might drive job dissatisfaction, we first summarised their pairwise associations by crude ORs, and then after combining those with high ORs and which appeared to measure closely related attributes (eg, job insecurity in illness vs job insecurity in health), we analysed associations with overall job dissatisfaction (again the dependent variable). As well as ORs, we computed the population attributable fractions (PAFs) for each perception, indicating the proportion of cases (people dissatisfied with their job) that might be eliminated if no one experienced that perception (ie, if all people had the same risk of dissatisfaction as in the reference category). We used the formula $P A F=p \times(R R-1) / R R$, where $p$ represented the proportion of cases exposed to that risk factor and RR the OR obtained through a logistic regression model adjusted for age and sex. PAFs were derived for the population as a whole, and also within strata defined separately by sex, age band, level of educational attainment and employment status.

Finally, with overall job dissatisfaction and negative perceptions of work treated as independent variables, we used logistic regression to assess associations with fair or poor SRH, depressive symptoms (CES-D score $\geq 16$ ) and poor well-being score (WEMWBS score lowest quintile). In this analysis, ORs were 
Table 1 Demographic and personal risk factors for job dissatisfaction

\begin{tabular}{|c|c|c|c|c|c|c|}
\hline \multirow[b]{2}{*}{ Risk factor } & \multirow[b]{2}{*}{ Number } & \multirow{2}{*}{$\begin{array}{l}\text { Number of } \\
\text { cases }\end{array}$} & \multicolumn{4}{|c|}{ Associations with overall job dissatisfaction } \\
\hline & & & ${ }^{*} \mathrm{OR}$ & $(95 \% \mathrm{Cl})$ & tOR & $(95 \% \mathrm{Cl})$ \\
\hline \multicolumn{7}{|l|}{ Sex } \\
\hline Male & 2649 & 199 & Reference & & Reference & \\
\hline Female & 2788 & 169 & 0.79 & (0.64 to 0.98$)$ & 0.76 & (0.61 to 0.94$)$ \\
\hline \multicolumn{7}{|l|}{ Age (years) } \\
\hline $50-54$ & 1843 & 140 & Reference & & Reference & \\
\hline $55-59$ & 2051 & 154 & 0.99 & (0.78 to 1.25$)$ & 0.97 & (0.76 to 1.24$)$ \\
\hline $60-64$ & 1543 & 74 & 0.61 & (0.46 to 0.82$)$ & 0.59 & (0.44 to 0.79 ) \\
\hline \multicolumn{7}{|l|}{ Area of GP practice } \\
\hline North East and North West & 1221 & 71 & Reference & & Reference & \\
\hline West Midlands & 745 & 52 & 1.22 & (0.84 to 1.76$)$ & 1.21 & (0.83 to 1.77$)$ \\
\hline East & 1245 & 95 & 1.34 & (0.98 to 1.85$)$ & 1.42 & (1.01 to 2.00$)$ \\
\hline South Central and West & 1809 & 114 & 1.09 & (0.80 to 1.48$)$ & 1.14 & (0.82 to 1.59$)$ \\
\hline London and South East & 417 & 36 & 1.54 & (1.01 to 2.34$)$ & 1.68 & (1.08 to 2.59 ) \\
\hline \multicolumn{7}{|l|}{ Deprivation (thirds) } \\
\hline Best & 1157 & 75 & Reference & & Reference & \\
\hline Intermediate & 1666 & 116 & 1.05 & (0.79 to 1.38$)$ & 1.16 & (0.83 to 1.62$)$ \\
\hline Worst & 2614 & 177 & 1.08 & (0.80 to 1.46$)$ & 1.12 & (0.83 to 1.51$)$ \\
\hline \multicolumn{7}{|l|}{ Educational level } \\
\hline School only & 1844 & 108 & Reference & & Reference & \\
\hline Vocational training certificate & 1749 & 127 & 1.22 & (0.94 to 1.60$)$ & 1.31 & (1.00 to 1.72 ) \\
\hline University degree or higher professional & 1844 & 133 & 1.21 & (0.93 to 1.57 ) & 1.25 & (0.95 to 1.63 ) \\
\hline \multicolumn{7}{|l|}{ Living alone } \\
\hline No & 4271 & 263 & Reference & & Reference & \\
\hline Yes & 1091 & 100 & 1.60 & (1.26 to 2.04 ) & 1.63 & (1.28 to 2.08 ) \\
\hline
\end{tabular}

adjusted for age, sex and educational attainment as a proxy for social class. Statistical analyses were carried out with Stata (V.14.0) software (StataCorp LP, College Station, Texas, USA).

\section{RESULTS}

From 8134 responders to the baseline questionnaire, we excluded 2625 who were not in paid work, and a further 72 who did not provide usable information about job satisfaction. This left a total of 2649 men and 2788 women who were included in the analysis. Within this sample, the prevalence of job dissatisfaction overall was $6.7 \%$, while that of negative perceptions of work that might contribute to job dissatisfaction ranged from $2.3 \%$ for often being criticised unfairly to $44.4 \%$ for job insecurity in illness.

Table 1 summarises the associations of overall job dissatisfaction with various demographic and personal risk factors. After adjustment for other variables, overall dissatisfaction was less common in women than men (OR $0.76,95 \%$ CI 0.61 to 0.94 ), and at older ages (OR $0.59,95 \%$ CI 0.44 to 0.79 for age $60-64$ vs 50-54 years). There were also geographical differences, the highest rates of dissatisfaction being reported in London and the South East (OR vs North East and North West 1.68, 95\% CI 1.08 to 2.59 ) and in the East (OR 1.42, 95\% CI 1.01 to 2.00). In addition, there was a higher prevalence of job dissatisfaction in participants who were more educated (ORs 1.25 to 1.31), and in those who lived alone (OR 1.63, 95\% 1.28 to 2.08).

Table 2 shows associations of overall job dissatisfaction with various aspects of employment. Dissatisfaction was most common among participants working for large employers (OR $2.25,95 \%$ CI 1.32 to 3.81 vs self-employed), and was less frequent in those who worked for $\leq 20 \mathrm{~h} /$ week or had a longer tenure of current employment. There was also a weak positive association with shift work (OR 1.37, 95\% CI 1.04 to 1.82 ).

All of the negative perceptions were mutually associated (see online supplementary table S1), ORs for pairwise associations being particularly high for: rarely/never having a feeling of achievement and rarely/never feeling appreciated (15.9); having difficult colleague(s) and often being criticised unfairly (9.8); and perceived job insecurity in illness and when well (8.4). It seemed likely that in these cases, the two perceptions reflected the same problem. Therefore, in subsequent analyses, new variables were created, defined by the presence of either or both perceptions (eg, either rarely/never having a feeling of achievement or rarely/never feeling appreciated or both).

Table 3 shows how overall job dissatisfaction related to different negative perceptions of work. The strongest association was with rarely/never feeling appreciated or a sense of achievement (OR 12.9 , 95\% CI 10.2 to 16.2 ), and although only $13.7 \%$ of participants made this complaint, the PAF was $53.6 \%(95 \% \mathrm{CI}$ $47.9 \%$ to $58.7 \%)$. An even higher PAF $(56.1 \%)$ was estimated for job insecurity, which was less strongly associated with overall dissatisfaction (OR 4.0, 95\% CI 3.1 to 5.1), but more prevalent (47.8\% of participants). Least important were lack of choice in activities (OR 2.7, PAF 22.4\%) and lack of support when in difficulty at work (OR 3.8, PAF 23.2\%).

Table 4 compares the possible contributions of different negative perceptions of work to overall job dissatisfaction in various subgroups of the study sample. There were no major differences between men and women, but at older ages, concerns about 
Table 2 Associations of job dissatisfaction with aspects of employment

\begin{tabular}{|c|c|c|c|c|c|c|}
\hline \multirow[b]{2}{*}{ Risk factor } & \multirow[b]{2}{*}{ Number } & \multirow{2}{*}{$\begin{array}{l}\text { Number of } \\
\text { cases }\end{array}$} & \multicolumn{4}{|c|}{ Associations with overall job dissatisfaction } \\
\hline & & & ${ }^{*} \mathrm{OR}$ & $(95 \% \mathrm{Cl})$ & tOR & $(95 \% \mathrm{Cl})$ \\
\hline \multicolumn{7}{|l|}{ Employment status } \\
\hline Self-employed & 884 & 30 & Reference & & Reference & \\
\hline Small employer (<500 staff) & 2543 & 153 & 1.89 & (1.27 to 2.83$)$ & 1.38 & (0.82 to 2.33$)$ \\
\hline Large employer ( $\geq 500$ staff) & 1984 & 181 & 2.90 & (1.95 to 4.31$)$ & 2.25 & (1.32 to 3.81$)$ \\
\hline \multicolumn{7}{|l|}{ Time worked same employer (years) } \\
\hline$<1$ & 336 & 34 & Reference & & Reference & \\
\hline 1 to 5 & 965 & 77 & 0.77 & (0.51 to 1.18$)$ & 0.86 & (0.54 to 1.35$)$ \\
\hline$>5$ years & 4071 & 255 & 0.60 & (0.41 to 0.88$)$ & 0.56 & (0.37 to 0.84$)$ \\
\hline \multicolumn{7}{|l|}{ Type of contract } \\
\hline Permanent & 4314 & 315 & Reference & & & \\
\hline Temporary/renewable & 320 & 22 & 0.96 & (0.61 to 1.51$)$ & & \\
\hline Not applicable (self-employed) & 775 & 29 & 0.48 & (0.33 to 0.72$)$ & & \\
\hline \multicolumn{7}{|l|}{ Salary } \\
\hline Fixed & 4502 & 324 & Reference & & Reference & \\
\hline Paid by output & 885 & 40 & 0.60 & (0.43 to 0.85$)$ & 1.03 & (0.65 to 1.63 ) \\
\hline \multicolumn{7}{|l|}{ Hours worked per week } \\
\hline$\leq 20$ & 804 & 34 & Reference & & Reference & \\
\hline$>20$ to 40 & 3218 & 230 & 1.59 & (1.09 to 2.32 ) & 1.68 & (1.09 to 2.59$)$ \\
\hline$>40$ & 1380 & 104 & 1.57 & (1.03 to 2.39$)$ & 1.75 & (1.09 to 2.82 ) \\
\hline \multicolumn{7}{|l|}{ Fixed time of starting work } \\
\hline Some or no work days & 1329 & 61 & Reference & & Reference & \\
\hline Most or all work days & 4091 & 306 & 1.73 & (1.30 to 2.30$)$ & 1.39 & (1.02 to 1.91$)$ \\
\hline \multicolumn{7}{|l|}{ Shift work } \\
\hline Sometimes/rarely/never & 4543 & 288 & Reference & & Reference & \\
\hline Often & 843 & 76 & 1.43 & (1.10 to 1.87 ) & 1.37 & (1.04 to 1.82$)$ \\
\hline \multicolumn{7}{|l|}{ Holidays } \\
\hline Some entitlement & 5254 & 356 & Reference & & Reference & \\
\hline No entitlement & 20 & 2 & 1.57 & (0.36 to 6.83 ) & 1.14 & (0.15 to 8.86$)$ \\
\hline \multicolumn{7}{|l|}{ Have a second paid job } \\
\hline No & 4612 & 317 & Reference & & Reference & \\
\hline Yes & 418 & 27 & 0.95 & (0.63 to 1.43 ) & 1.00 & (0.65 to 1.53 ) \\
\hline
\end{tabular}

working hours seemed to be less of a problem than in younger participants (PAF 24.6\% at age 60-64 years vs $40.8 \%$ at age 50-54 years). In comparison with those whose education had not progressed beyond school, overall dissatisfaction among participants with a university degree or higher professional qualification appeared less likely to be driven by concerns about pay, lack of appreciation or a feeling of achievement, or lack of choice in occupational activities. Dissatisfaction among the selfemployed appeared to be driven mainly by concerns about working hours and pay.

Table 3 Contributions of negative perceptions of work to overall job dissatisfaction

\begin{tabular}{|c|c|c|c|c|c|c|}
\hline \multirow[b]{2}{*}{ Perception } & \multicolumn{2}{|c|}{ Number (\%) reporting perception } & \multicolumn{4}{|c|}{$\begin{array}{l}\text { Association with overall job } \\
\text { dissatisfaction }\end{array}$} \\
\hline & $\begin{array}{l}\text { Among all participants } \\
(n=5437)\end{array}$ & $\begin{array}{l}\text { Among participants with overall } \\
\text { job dissatisfaction }(n=368)\end{array}$ & ${ }^{*} \mathrm{OR}$ & $(95 \% \mathrm{Cl})$ & tPAF & $(95 \% \mathrm{Cl})$ \\
\hline Dissatisfied with working hours & $594(11.0)$ & $164(44.7)$ & 8.5 & (6.8 to 10.7$)$ & 37.7 & (32.3 to 42.7 ) \\
\hline Dissatisfied with pay & $1230(22.7)$ & $226(61.6)$ & 6.4 & (5.2 to 8.1$)$ & 50.2 & (43.7 to 56.0$)$ \\
\hline Rarely/never feel appreciated and/or sense of achievement & $745(13.7)$ & $221(60.1)$ & 12.9 & (10.2 to 16.2$)$ & 53.6 & (47.9 to 58.7 ) \\
\hline Rarely/never support when in difficulty & $616(12.9)$ & $114(33.2)$ & 3.8 & (3.0 to 4.9 ) & 23.2 & (17.7 to 28.3 ) \\
\hline Rarely/never have choice in activities & $1083(20.0)$ & $138(37.7)$ & 2.7 & (2.1 to 3.4$)$ & 22.4 & (16.2 to 28.1$))$ \\
\hline One or more colleagues difficult and/or often criticised unfairly & $1781(32.8)$ & $239(65.0)$ & 4.2 & (3.3 to 5.2 ) & 47.5 & (40.0 to 54.1$)$ \\
\hline Job insecure in illness and/or when well & $2594(47.8)$ & $284(77.2)$ & 4.0 & (3.1 to 5.1 ) & 56.1 & (47.3 to 63.4 ) \\
\hline
\end{tabular}




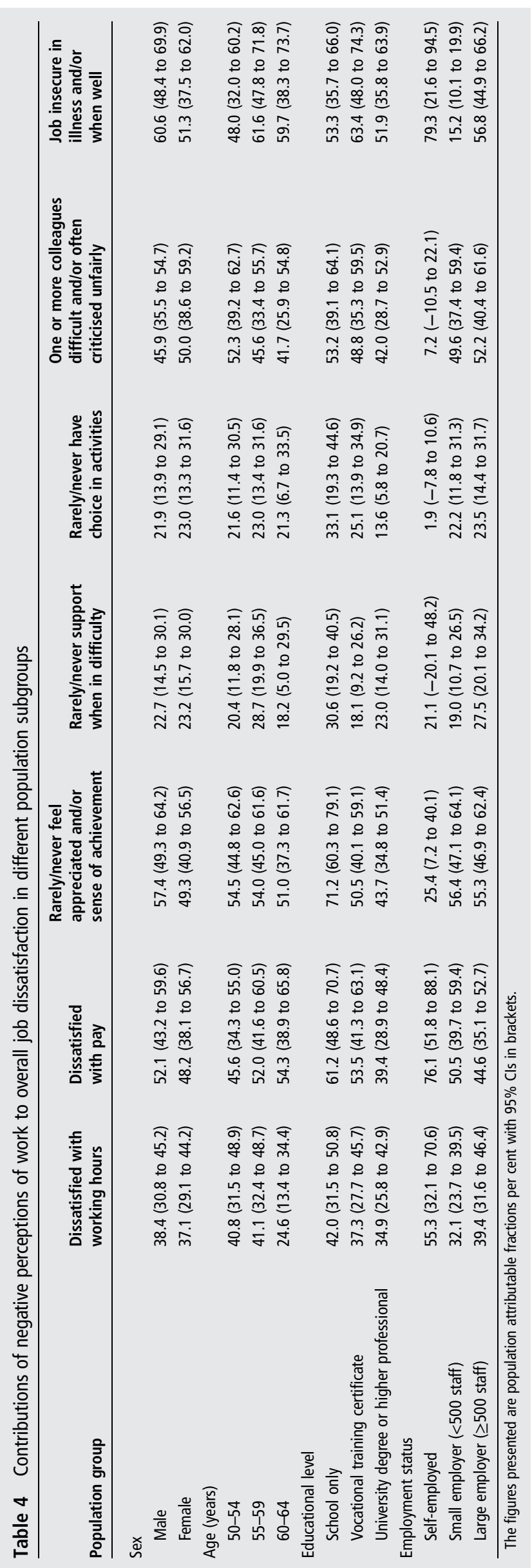

Table 5 summarises the relationship of overall job dissatisfaction and contributing negative perceptions to three health outcomes-fair/poor SRH, depression (CES-D score $\geq 16$ ) and poor well-being (lowest quintile of WEMWBS score). Overall job dissatisfaction was associated with each of the health outcomes, the ORs (3.16, 5.26 and 5.52, respectively) being higher than for any of the individual perceptions. Among the perceptions, lack of support at work appeared to have little effect (ORs 0.94 to 1.22), whereas the three health outcomes were each significantly associated with difficulty with colleagues/feeling unfairly criticised and job insecurity, while all but well-being were significantly associated with dissatisfaction about pay. Not feeling appreciated or a sense of achievement was also associated with all three measures of health, and particularly with poor wellbeing (OR 3.18, 95\% CI 2.25 to 4.49). Dissatisfaction with working hours related to depression and poor well-being but not to SRH, whereas lack of choice in occupational activities showed no relationship to poor well-being but was weakly associated with fair/poor SRH and depression.

\section{DISCUSSION}

Within our study sample, the main perceptions of work driving job dissatisfaction among employees were lack of appreciation and/or a feeling of achievement, and difficulty with colleagues at work and/or feeling unfairly criticised, whereas in the selfemployed they were job insecurity and dissatisfaction with pay. Overall job dissatisfaction was more common in men than women, below age 60 years, in London and the South East, and in those working for large employers. It was also associated with longer education and living alone. Most potential drivers of job dissatisfaction contributed to overall associations with worse SRH, depression and poor well-being, but lack of support and choice in work had relatively little impact.

Potential strengths and limitations have to be considered when interpreting these findings. A notable strength was the large, geographically dispersed, population-based sampling strategy. Almost everyone in Britain registers with a general practice for healthcare free at the point of delivery, so the patient lists of general practices provide a comprehensive and representative sampling frame. The response rate at baseline was relatively low and responders tended to be somewhat older, more affluent and more often female than non-responders, although the sample's profile approximated reasonably to national statistics for this age band. ${ }^{18}$ The prevalence of overall job dissatisfaction could have been underestimated or overestimated if those dissatisfied with their work were less or more likely to participate. However, associations of job dissatisfaction with the variables of interest (demographic and workplace factors, its occupational components, and the report's health outcomes) would only be biased if they differed importantly between responders and nonresponders. We have no reason to expect this. Moreover, questions on job dissatisfaction and its potential drivers formed only a small part of a larger question set (in all 91 questions and up to 154 responses), and are unlikely therefore to have influenced decisions to participate in the research.

A further strength stemming from population sampling was the opportunity (assuming causal relationships) to estimate PAFs for negative perceptions contributing to job dissatisfaction, overall and within strata with differing characteristics. To our knowledge, such information has never previously been available. New insights are offered into the relative importance of different potential drivers at a population level and within important subgroups. 
Table 5 Associations of health outcomes with overall job dissatisfaction and its negative perceptions of work

\begin{tabular}{|c|c|c|c|c|c|c|c|c|c|}
\hline & \multicolumn{3}{|c|}{ Fair/poor self-rated health } & \multicolumn{3}{|c|}{ CES-D score $\geq 16$} & \multicolumn{3}{|c|}{ WEMWBS score poor $(<32)$} \\
\hline & $\begin{array}{l}\text { Cases } \\
\text { exposed }\end{array}$ & *OR & $(95 \% \mathrm{Cl})$ & $\begin{array}{l}\text { Cases } \\
\text { exposed }\end{array}$ & ${ }^{*} \mathrm{OR}$ & $(95 \% \mathrm{Cl})$ & $\begin{array}{l}\text { Cases } \\
\text { exposed }\end{array}$ & *OR & $(95 \% \mathrm{Cl})$ \\
\hline Overall job dissatisfaction & 138 & 3.16 & (2.52 to 3.97$)$ & 208 & 5.26 & (4.21 to 6.58$)$ & 56 & 5.52 & (3.97 to 7.67 ) \\
\hline \multicolumn{10}{|l|}{ Negative perceptionst } \\
\hline Dissatisfied with working hours & 161 & 1.13 & $(0.90$ to 1.42$)$ & 264 & 1.92 & (1.56 to 2.36$)$ & 59 & 1.78 & (1.24 to 2.56$)$ \\
\hline Dissatisfied with pay & 352 & 1.71 & (1.44 to 2.03$)$ & 463 & 1.59 & $(1.35$ to 1.87$)$ & 95 & 1.31 & (0.95 to 1.81$)$ \\
\hline Rarely/never appreciated and/or sense of achievement & 225 & 1.47 & (1.19 to 1.81$)$ & 337 & 1.99 & $(1.64$ to 2.42$)$ & 95 & 3.18 & (2.25 to 4.49$)$ \\
\hline Rarely/never support when in difficulty & 139 & 0.94 & (0.75 to 1.18$)$ & 212 & 1.20 & (0.97 to 1.48$)$ & 49 & 1.22 & (0.84 to 1.78$)$ \\
\hline Rarely/never have choice in activities & 275 & 1.28 & (1.07 to 1.54$)$ & 359 & 1.12 & (0.95 to 1.33$)$ & 68 & 0.93 & (0.66 to 1.29$)$ \\
\hline One or more colleagues difficult and/or often criticised unfairly & 425 & 1.53 & (1.31 to 1.79$)$ & 607 & 1.74 & (1.51 to 2.01$)$ & 118 & 1.63 & (1.20 to 2.21$)$ \\
\hline Job insecure in illness and/or when well & 582 & 1.58 & (1.35 to 1.85 ) & 785 & 1.67 & (1.44 to 1.92$)$ & 149 & 1.56 & (1.14 to 2.15 ) \\
\hline
\end{tabular}

Set against these strengths, it should be noted that our analysis was based on the baseline phase of the HEAF study and crosssectional in nature, imposing limits on interpretation. Thus, for example, while poor quality of relationships at work and lack of fulfilment are credible sources of job dissatisfaction, we cannot exclude the possibility that disaffection with work may have soured some people's working relationships with others. Likewise, while job dissatisfaction may well lead to poorer selfassessed health, circumstances can be imagined in which poor health could erode satisfaction with one's own work performance and lead to overall job dissatisfaction. Survivorship effects are also evident in this cross-sectional analysis: for example, the inverse relationship between dissatisfaction and job tenure probably reflects a propensity of people to remain longer in a job that appeals to them.

A further potential limitation stems from the challenge inherent in measuring a complex multifaceted phenomenon. Different approaches have been taken to assessment of job dissatisfaction across studies. Some investigations have used elaborate scales containing many questions. By contrast, we assessed overall job dissatisfaction using a single item. However, Wanous et $a l^{23}$ have conducted a meta-analysis to assess the validity of single-item scales and concluded that the correlation between single-item and multi-item scales is acceptable.

Such complexity is a reason for also studying the potential drivers of job dissatisfaction. Our study encompassed only some of the many facets that have been proposed. ${ }^{24} 25$ In particular, we did not consider 'intrinsic' determinants of dissatisfaction, such as negative affectivity and other aspects of personality, although several theoretical models have been developed that are based on such attributes. ${ }^{26}$ Collecting the extra detail was not feasible given the broad aims of the HEAF study, but confounding by personality differences between groups is unlikely to have importantly influenced findings in our area of primary interest.

In focusing on risk factors in the workplace that might be avoidable, we included some facets that have been little studied previously but appeared of interest a priori. Thus, for example, existing literature on the impact of perceived lack of recognition $^{15} 16$ and cohesiveness of working relationships ${ }^{27}$ is fairly small.

Relationships of job dissatisfaction to younger age and male sex are well established by other research and in agreement with our own findings. Others' findings also accord with ours on several less frequently studied demographic and occupational associations, such as shorter job tenure, ${ }^{28}$ longer working hours, ${ }^{27} 2930$ working in large establishments ${ }^{29} 30$ and higher educational attainment, ${ }^{29}{ }^{30}$ relationships we have been able to confirm specifically in a sample of older workers. The greater propensity towards job dissatisfaction of Londoners and those living in the South East of England is a novel discovery, however. Among the possible drivers we considered, our findings on autonomy and decision latitude, ${ }^{15}{ }^{31}$ working relationships, ${ }^{27}$ feeling undervalued with lack of recognition, ${ }^{15} 16$ and job insecurity ${ }^{29} 32$ are similar to those in a relatively small number of other reports, although supplemented here by quantification of effects at the population level. They are also compatible with some reports based on effort-reward imbalance and job dissatisfaction, such as that by de Jonge et al, ${ }^{33}$ which defined occupational rewards in terms of satisfaction with pay, social support and job security.

Associations between job dissatisfaction and psychological ill health are well recognised. Thus, in a meta-analysis of 485 mainly cross-sectional studies, Faragher et $a l^{17}$ found clear-cut correlations between job dissatisfaction and anxiety, depression and poorer general mental health. However, the impact on selfreported health of the different negative perceptions that drive job dissatisfaction has been unclear, and table 5 provides useful new information.

Studies in older workers (in the age bands of the HEAF study) have been uncommon to date and their focus has differed from that presented here. However, in the Survey of Health, Aging and Retirement in Europe (SHARE), a large cohort of 50-64-year olds from 10 European countries, overall job dissatisfaction was assessed using a very similar question to our own and a similar estimate of prevalence was derived. ${ }^{10}$ In the same survey, in keeping with our findings, job satisfaction was greater among women, with advancing age, in those who felt there was recognition for the job and in those perceiving their job to be secure $^{34}$; poor job quality (defined in part to include job dissatisfaction) was strongly associated with poor SRH and depression. ${ }^{35}$

Our data suggest that feeling unappreciated, lacking a sense of achievement at work, perceptions about having critical colleagues, being dealt with unfairly and job insecurity, and concerns about pay may be important population drivers of overall job dissatisfaction, albeit with variation between subgroups. As such, 
they represent potential targets for interventions based on improved employment policies.

The impetus for employers to intervene is likely to be driven by costs and benefits, one consideration being the likely effect of job dissatisfaction on labour force participation. Workers from the SHARE study who were dissatisfied with their job were more likely to express retirement intentions ${ }^{36}$ and twice as likely actually to retire 2 years later. ${ }^{10}{ }^{11}$ Job dissatisfaction was the strongest predictor of early retirement, ${ }^{10}{ }^{11}$ suggesting that the impact could be material. Findings in mixed-age workforces are less clear-cut, however, with some reports indicating increased labour turnover ${ }^{45}$ but others indicating only a small effect. ${ }^{6}$ Further research is required in older workers, since their employment outcomes may differ from those in other age bands. Moreover, while dissatisfied younger workers may seek alternative employment, dissatisfied older workers may be lost permanently to the workforce.

Participants of the HEAF study are being followed up annually with linkage to the CPRD, and this prospective phase should provide much needed additional data on how job dissatisfaction influences future employment, how changes in work circumstances affect job dissatisfaction and health over time, and whether job dissatisfaction has long-term effects on health, including doctor-recorded as well as self-reported health outcomes.

\section{Author affiliations \\ ${ }^{1}$ MRC Lifecourse Epidemiology Unit, University of Southampton, Southampton, UK \\ ${ }^{2}$ Arthritis Research UK/MRC Centre for Musculoskeletal Health and Work, University of Southampton, Southampton, UK \\ ${ }^{3}$ NIHR Collaboration for Leadership in Applied Health Research and Care Wessex, Newcastle upon Tyne, UK \\ ${ }^{4}$ Institute of Neuroscience, Newcastle University, Newcastle upon Tyne, UK \\ ${ }^{5}$ NIHR Newcastle Biomedical Research Centre, Newcastle University and Newcastle upon Tyne Hospitals NHS Foundation Trust, Newcastle upon Tyne, UK \\ ${ }^{6}$ Department of Psychology, Centre for Cognitive Ageing and Cognitive Epidemiology, University of Edinburgh, Edinburgh, UK \\ ${ }^{7}$ Centre for Research on Ageing, University of Southampton, Southampton, UK \\ ${ }^{8}$ Farr Institute, University of Manchester, Manchester, UK}

Acknowledgements The authors wish to thank the CPRD and the 24 general practices that have supported data collection; also, the staff of the MRC LEU who provided invaluable support with data entry and computing (notably Helena Demetriou and Vanessa (ox).

Contributors KTP and DC identified the study questions and designed the study and its measuring instruments. KTP supervised data collection, and with SD and DC, planned the analyses. SD conducted the analyses, wrote the first draft of the paper and shared with KTP in reviewing the existing literature. KW-B, ECH, CL, AAS, CRG, $M E$, TVS and CC contributed to the study's design, content, measuring instruments and plan of execution. Additionally, ECH and CL led in data collection, cleaning and preparation, and the enlistment of participating general practices. All authors read and approved the final manuscript.

Funding The HEAF study is funded by the Medical Research Council (though core programme support), and by grant awards from Arthritis Research UK, the Economic and Social Research Council and Medical Research Council.

Competing interests None declared.

Patient consent Obtained.

Ethics approval NHS Research Ethics Committee North West-Liverpool East.

Provenance and peer review Not commissioned; externally peer reviewed.

\section{REFERENCES}

1 OECD. Trends in retirement and in working at older Ages. Pensions at a glance 2011: retirement-income systems in OECD and G20 Countries. OECD Publishing, 2011. http://dx.doi:10.1787/pension_glance-2011-6-en (accessed 19 Jan 2016)

2 United Nations Department for Economic and Social Affairs, Population Division. World population ageing 2013. New York: United Nations, 2013. http://www.un.
org/en/development/desa/population/publications/ageing/WorldPopulationAgeing Report2013.shtml (accessed 19 Jan 2016).

3 Cooke M. Policy changes and the labour force participation of older workers: evidence from six countries. Can J Aging 2006;25:387-400.

4 Porter LW, Steers RM, Mowday RT, et al. Organizational commitment, job satisfaction, and turnover among psychiatric technicians. J Appl Psychol 1974;59:603-9.

5 Tett RP, Meyer JP. Job satisfaction, organizational commitment, turnover intention, and turnover: path analyses based on meta-analytic findings. Pers Psychol 1993:46:259-93.

6 Mobley WH. Intermediate linkages in the relationship between job satisfaction and employee turnover. J Appl Psychol 1977;62:237-40.

7 Shields MA, Ward M. Improving nurse retention in the National Health Service in England: the impact of job satisfaction on intentions to quit. J Health Econ 2001;20:677-701.

8 Mein G, Martikainen P, Stansfeld SA, et al. Predictors of early retirement in British civil servants. Age Ageing 2000;29:529-36.

9 Kosloski K, Ekerdt D, DeViney $S$. The role of job-related rewards in retirement planning. J Gerontol B Psychol Sci Soc Sci 2001;56:P160-9.

10 Schnalzenberger $M$, Schneeweis $N$, Winter-Ebmer $R$, et al. Job quality and retirement decisions. In: Börsch-Supan $A$, Brugiavini $A$, Jürges $H$, Kapteyn $A$, Mackenbach J, Siegrist J, Weber G, eds. First results from the survey of health, ageing and retirement in Europe (2004-2007): starting the longitudinal dimension. MEA, 2008:215-21. http://www.share-project.org/nc/publications/books0.html (accessed 19 Jan 2016).

11 Schnalzenberger M, Schneeweis N, Winter-Ebmer R, et al. Job quality and employment of older people in Europe. Labour 2014;28:141-62.

12 Hoogendoorn WE, Bongers PM, de Vet HC, et al. High physical work load and low job satisfaction increase the risk of sickness absence due to low back pain: results of a prospective cohort study. Occup Environ Med 2002;59:323-8.

13 Böckerman P, Ilmakunnas P. Interaction of working conditions, job satisfaction, and sickness absences: evidence from a representative sample of employees. Soc Sci Med 2008;67:520-8.

14 Roelen CA, Koopmans PC, Notenbomer A, et al. Job satisfaction and sickness absence: a questionnaire survey. Occup Med 2008;58:567-71.

15 Evans S, Huxley P, Gately C, et al. Mental health, burnout and job satisfaction among mental health social workers in England and Wales. Br I Psychiatry 2006; $188: 75-80$

16 Van Ham I, Verhoeven AA, Groenier KH, et al. Job satisfaction among general practitioners: a systematic literature review. Eur J Gen Pract 2006;12: $174-80$.

17 Faragher EB, Cass M, Cooper CL. The relationship between job satisfaction and health: a meta-analysis. Occup Environ Med 2005;62:105-12.

18 Palmer KT, Walker-Bone K, Harris EC, et al. Health and Employment after Fifty (HEAF): a new prospective cohort study. BMC Public Health 2015;15:1071.

19 Department for Communities and Local Government. English Indices of Deprivation 2010. Neighbourhoods Statistical Release, 24 November 2011, ISBN: 9781409829249. https://www.gov.uk/government/statistics/ english-indices-of-deprivation-2010 (accessed 19 Jan 2016).

20 Eriksson I, Undén AL, Elofsson S. Self-rated health. Comparisons between three different measures. Results from a population study. Int I Epidemiol 2001:30:326-33.

21 Radloff LS. The CES-D scale a self-report depression scale for research in the general population. Appl Psychol Meas 1977;1:385-401.

22 Tennant $R$, Hiller L, Fishwick R, et al. The Warwick-Edinburgh mental well-being scale (WEMWBS): development and UK validation. Health Qual Life Outcomes 2007;5:63.

23 Wanous JP, Reichers AE, Hudy MJ. Overall job satisfaction: how good are single-item measures? J Appl Psychol 1997;82:247-52.

24 Spector PE. Job satisfaction: application, assessment, causes and consequences. Thousand Oaks, CA: SAGE, 1997.

25 Hulin CL, Judge TA. Job attitudes. In: Borman WC, Ligen DR, Klimoski RL, eds. Handbook of psychology: industrial and organizational psychology. Hoboken, NJ: Wiley, 2003:255-76

26 Staw BM, Bell NE, Clausen JA. The dispositional approach to job attitudes: a lifetime longitudinal test. Adm Sci Q 1986;31:56-77.

27 Adams A, Bond S. Hospital nurses' job satisfaction, individual and organizational characteristics J Adv Nurs 2000;32:536-43.

28 Brush DH, Moch MK, Pooyan A. Individual demographic differences and job satisfaction. J Organ Behav 1987;8:139-55.

29 Gazioglu S, Tansel A. Job satisfaction in Britain: individual and job related factors. Appl Econ 2006;38:1163-71.

30 Clark AE. Job satisfaction in Britain. Br J Ind Relat 1996;34:189-217.

31 Eichar DM, Norland S, Brady EM, et al. The job satisfaction of older workers. J Organ Behav 1991;12:609-20. 
32 Heaney CA, Israel BA, House JS. Chronic job insecurity among automobile workers: effects on job satisfaction and health. Soc Sci Med 1994;38: 1431-7.

33 de Jonge J, Bosma $\mathrm{H}$, Peter $\mathrm{R}$, et al. Job strain, effort-reward imbalance and employee well-being: a large scale cross-sectional study. Soc Sci Med 2000; 50: 1317-27.

34 Bonsang $E$, van Soest A. Satisfaction with job and income among older individuals across European countries. Soc Indic 2012;105:227-54.
35 Siegrist JO, von dem Knesebeck O, Wahrendorf M. Quality of employment and well-being. In: Börsch-Supan A, Brugiavini A, Jürges $\mathrm{H}$ et al, eds. Health, ageing and retirement in Europe-first results from the survey of health, ageing and retirement in Europe. Mannheim: Mannheim Research Institute for the Economics of Aging (MEA), 2005:192-8.

36 Siegrist J, Wahrendorf $M$, von dem Knesebeck 0 , et al. Quality of work, well-being and intended early retirement of older employees: baseline results from the SHARE Study. Eur J Public Health 2007;17:62-8. 